\title{
Phosphorus acquisition from phosphate rock by soil cover crops, maize, and a
}

\section{buckwheat-maize cropping system}

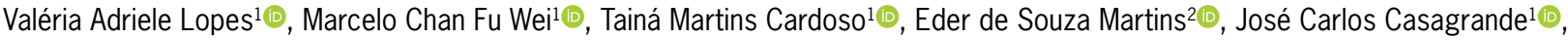 \\ Eduardo Dal'Ava Mariano ${ }^{*}$ (1)
}

\author{
${ }^{1}$ UFSCar/CCA, Rod. SP 330, km 174, C.P. 153 - 13600 \\ 970 - Araras, SP - Brasil. \\ Embrapa Cerrados, Rod. BR 020, km 18, C.P. $8223-$ \\ 73310-970 - Planaltina, DF - Brasil. \\ *Corresponding author <edmariano@ufscar.br>
}

Edited by: Anoop Kumar Srivastava

Received October 08, 2020

Accepted March 30, 2021

\begin{abstract}
Alternatives to enhance the consensual low phosphorus (P) use efficiency of agriculture may include use of phosphate rock (PR) and plant species with unequal ability to get soil and rock $P$ interplanted in cropping systems to allow plants with higher ability to facilitate access to $P$ of plants with lower ability. This study investigated (i) the maize and three soil cover crops on their capacity to acquire $P$ from $P R$ and (ii) measured $P$ acquisition of maize interplanted with the soil cover crop with the highest capacity to acquire $P$ shown in (i). Experiments were carried out in a greenhouse, with plants grown in single and mixed cropping in pots containing a sandy, low-P soil amended with Monocalcium Phosphate (McP) or the Brazilian PR Itafós. Plant biomass production with $\mathrm{PR}$, in relation to $\mathrm{McP}$, was $83.7 \%$ for buckwheat, $83.6 \%$ for forage radish, $51.8 \%$ for maize, and $0.3 \%$ for pigeon pea. Buckwheat showed capacity of acquiring P from PR; nevertheless, it did not increase growth or P nutrition of maize interplanted in the soil amended with PR, showing no significant $P$ facilitation. The soil amended with McP showed competition between the two plants in the pots. Maize had a greater growth in mixed than in single cropping and this occurred at the expenses of buckwheat. Despite the P mobilization potential of buckwheat, its simple interplanting with maize did not produce positive results.

Keywords: P efficiency, competition, facilitation, intercropping
\end{abstract}

\section{Introduction}

The use of phosphorus $(\mathrm{P})$ in agriculture is rather inefficient in most cases. Only part of the $\mathrm{P}$ applied to fertilize the soils is taken up by plants along the years and $\mathrm{P}$ accumulation in poorly soluble inorganic and organic compounds contributes definitively to its inefficient use (Withers et al., 2018). Alternatives to increase P use efficiency include plants and microorganisms involved in strategies to enhance desorption, solubilization, and mineralization of $\mathrm{P}$ forms, improve plant internal $\mathrm{P}$ use efficiency, and reduce $\mathrm{P}$ harvest index of crops (Hallama et al., 2019; Manschadi et al., 2014). The use of phosphate rock $(\mathrm{PR})$ to fertilize soils may be complementary to these strategies, because of its more gradual $\mathrm{P}$ release, higher residual effect, and lower relative cost (Chien et al., 2011). The agronomic effectiveness of PRs, however, is inconstant and successful outcomes with their use are more likely when proper combinations of PR, soil, plant species, soil organisms, cropping system, and soil management are adopted (Pavinato et al., 2017; Prochnow et al., 2006; Stamford et al., 2007; 2016; Yagi et al., 2020). Pavinato et al. (2017) conducted a study on a 3-year maize and winter cover crops rotation under no-tillage system and observed similar amounts of plant biomass production and $\mathrm{P}$ uptake by white clover, black oat, forage radish, ryegrass, common vetch, and white lupin between soils fertilized with single superphosphate (SSP) and an Algerian PR. The PR was as effective as SSP to increase maize yield in the first two seasons and was more effective than SSP in the third season.
Intercropping has been used in agriculture to enhance resource-use efficiency, and particularly the legume-cereal intercropping is widely adopted worldwide. Maize, an important staple food in Latin America, is intercropped on $60 \%$ of the area of smallholder farmers. Intercropping legumes and cereals often improves nitrogen $(\mathrm{N})$ nutrition and cereal growth (Brooker et al., 2015; Duchene et al., 2017); however, differently from $\mathrm{N}$, the effects of intercropping on $\mathrm{P}$ acquisition and other nutrients are largely unknown. Few studies have investigated combinations of plant species that cause effective changes in soil $\mathrm{P}$ dynamics and effectiveness of PRs in mixed cropping systems.

Legumes and non-legumes commonly used as soil cover crops in Brazil are well-known for their capacity to acquire $\mathrm{P}$ from compounds of low water solubility (e.g. buckwheat, oat, oilseed rape, white lupin) (Hallama et al., 2019; Pearse et al., 2006) and, hypothetically, good candidates in intercropping systems. Improved acquisition of soil nutrients by plants in (agro) ecosystems may result from facilitation, an interspecific root interaction process that occurs when one species increases soil nutrient availability and the neighbor species is benefitted (Hauggaard-Nielsen and Jensen, 2005). Interspecific root interactions, however, may also occur in the form of competition for nutrients and other below ground resources. This study (i) evaluated maize and three soil cover crop species on their capacity to acquire $\mathrm{P}$ from a $P R$, and (ii) measured $P$ acquisition of maize interplanted with the soil cover crop with the highest capacity to mobilize P shown in (i). 


\section{Materials and Methods}

Two experiments were carried out in a greenhouse with plants of four species grown in a single (Experiment 1) and mixed cropping (Experiment 2) in pots containing a sandy, low-P soil amended with two phosphate sources of different solubilities in water (see below). The soil was collected from the subsoil of an Arenosol, or Entisol (Quartzipsamment) in the USA Soil Taxonomy, and had the following physical and chemical attributes: 8.0 $\mathrm{g} \mathrm{kg}^{-1}$ of organic matter, $920 \mathrm{~g} \mathrm{~kg}^{-1}$ of sand, $10 \mathrm{~g} \mathrm{~kg}^{-1}$ of silt, $70 \mathrm{~g} \mathrm{~kg}^{-1}$ of clay, $\mathrm{pH}-\mathrm{CaCl}_{2}$ of $4.7,6.0 \mathrm{mg} \mathrm{dm} \mathrm{m}^{-3}$ of resin-extractable $\mathrm{P}, 5.0 \mathrm{mmol}_{\mathrm{c}} \mathrm{dm}^{-3}$ of calcium and $21.6 \mathrm{mmol}_{\mathrm{c}} \mathrm{dm}^{-3}$ of cation exchange capacity. Prior to its use, the soil material was sieved, homogenized, and incubated with calcium carbonate $\left(\mathrm{CaCO}_{3}\right)$ to neutralize partly its acidity. The rate of $\mathrm{CaCO}_{3}$ application, 0.17 $\mathrm{g} \mathrm{kg}^{-1}$ soil, was chosen from a titration curve obtained by an incubation test with $\mathrm{CaCO}_{3}$. This rate showed a substantial decrease of active soil acidity, reaching $\mathrm{pH} 5.8$, without unduly increasing its Ca concentration $\left(3.4 \mathrm{mmol}_{\mathrm{c}}\right.$ $\mathrm{kg}^{-1}$ addition), which could affect dissolution of PR. After 30 days of incubation, the soil was fertilized with macro and micronutrients. Aliquots of diverse stock solutions were applied to portions of $1.8 \mathrm{~kg}$ of soil to produce the following concentrations of the nutrients $\left(\mathrm{mg} \mathrm{kg}^{-1}\right): 100 \mathrm{~N}$ (50 NH $4: 50 \mathrm{NO}_{3}$ ), $87 \mathrm{P}, 100 \mathrm{~K}, 50 \mathrm{Mg}, 50 \mathrm{~S}, 0.5 \mathrm{~B}, 1.5 \mathrm{Cu}$, $5.0 \mathrm{Fe}$ (as Fe-Ethylenediaminetetraacetic acid), 3.0 Mn, $0.1 \mathrm{Mo}$, and 5.0 Zn. Despite this initial fertilization, two other fertilizations with $50 \mathrm{mg} \mathrm{kg}^{-1} \mathrm{~N}$ and $50 \mathrm{mg} \mathrm{kg}^{-1} \mathrm{~K}$ each were applied to the soil at days 21 and 38 of plant growth. The salts used were $\mathrm{NH}_{4} \mathrm{NO}_{3}$ and $\mathrm{KCl}$.

Two $\mathrm{P}$ sources were used to amend the soil, the reagent-grade Monocalcium Phosphate (McP), considered the reference source, and the Brazilian PR Itafós, an alternative $\mathrm{P}$ source. This is a sedimentary rock, with concentrations of $\mathrm{P}$ fractions of $58.9 \mathrm{~g} \mathrm{~kg}^{-1}$ total $\mathrm{P}, 35.4 \mathrm{~g} \mathrm{~kg}^{-1} \mathrm{P}$ soluble in $2 \%$ citric acid, $34.9 \mathrm{~g}$ $\mathrm{kg}^{-1} \mathrm{P}$ soluble in $2 \%$ formic acid and with the following relative particle size distribution: $54.8 \%<0.30 \mathrm{~mm}$, $31.3 \% 0.30-0.84 \mathrm{~mm}, 13.6 \% 0.84-2.00 \mathrm{~mm}, 0.30 \%$ $>2.00 \mathrm{~mm}$. Both $\mathrm{P}$ sources were incorporated into the soil at a rate of $87 \mathrm{mg} \mathrm{kg}^{-1}$ of $\mathrm{P}$, considering the total $\mathrm{P}$ fraction for PR. Furthermore, a control treatment with no added $\mathrm{P}(\mathrm{NaP})$ was used.

The pots consisted of a piece of PVC pipe $75 \mathrm{~mm}$ in diameter and $300 \mathrm{~mm}$ in height, closed at the bottom with two layers of a fine nylon mesh. Each pot was filled with $1.8 \mathrm{~kg}$ of soil amended with the respective $\mathrm{P}$ treatment (soil density $=1.36$ ). The soil, moistened during addition of $\mathrm{CaCO}_{3}$ and fertilization, had its moisture maintained close to field capacity, near $15 \%$ $\left(\mathrm{w} \mathrm{w}^{-1}\right)$ throughout the experimental period by daily weighing and replenishing with demineralized water.

The four plant species studied were buckwheat (Fagopyrum esculentum cv. IPR 91-Baili), forage radish (Raphanus sativus cv. IPR 116), maize (Zea mays L. cv. IAC 8390), and pigeon pea (Cajanus cajan L. cv. Fava Larga).
In Experiment 1, plants of only one species were grown in the pots (two plants per pot). The combination of four plant species with three $\mathrm{P}$ sources resulted in a two-way factorial of 12 treatments. In Experiment 2, plants of two species were grown together in the pots (two plants per pot, one of each species). The plant species used were maize and species with the highest capacity to mobilize P shown in Experiment 1. The combination of two plant species with three $\mathrm{P}$ sources and two cropping systems (single and mixed) resulted in a three-way factorial of 12 treatments. The experiments were set up in a completely randomized design with three replicates.

Seeds of the plant species were sown directly into the soil. Five days after emergence, plants were thinned to two plants per pot, either two plants of the same species (Experiment 1) or one plant of each species (Experiment 2). Plants were grown in the pots for 45 days in both experiments. At the end of this period, plants were harvested and separated into roots and shoots. Roots of the two plants grown together could not be separated from each other and were thus kept as one root system, washed with water to remove the adhering soil and both roots and shoots were dried in an oven at $65{ }^{\circ} \mathrm{C}$ for $72 \mathrm{~h}$. The dried roots and shoots were weighed separately, ground, and digested in a mixture of nitric and perchloric acid. Digests were analyzed on $\mathrm{P}$ by atomic absorption spectrometry (AAS). The total plant $\mathrm{P}$ content was calculated from root and shoot biomass and the respective $\mathrm{P}$ concentration.

The Agronomic Efficiency Index (AEI) of PR was calculated as AEI $=[$ (biomass produced at $\mathrm{PR}$ treatment - biomass produced at $\mathrm{NaP}$ treatment)/(biomass produced at $\mathrm{McP}$ treatment - biomass produced at $\mathrm{NaP}$ treatment)] $\times 100$. The other variable studied, biomass $\mathrm{P}$ content, was also used to calculate AEI.

Two- and three-ways analyses of variance (ANOVA) were done to assess the effects of plant species, $\mathrm{P}$ source, and cropping system on biomass production and $\mathrm{P}$ accumulation by plants. The Tukey multiple comparison test at the 0.05 probability degree was used to compare means. The residual analysis was performed to confirm the adequacy of the statistical model and detect violations of the assumptions underlying the random errors. These analyses were done with the R software (2017 The R Foundation for Statistical Computing Platform).

\section{Results and Discussion}

Experiment 1 - This experiment assessed the capacity of plants to mobilize $\mathrm{P}$ from the Brazilian PR Itafós. Data collected revealed a distinct ability of the four species studied to use this $\mathrm{PR}$ as $\mathrm{P}$ source. The plant species interacted with the $\mathrm{P}$ sources resulting in highly significant differences in plant biomass and $\mathrm{P}$ accumulation of shoots and roots. Small amounts of biomass were accumulated systematically in shoots and roots with no $\mathrm{P}$ application, but all species accumulated 
significantly more biomass with $\mathrm{P}$ application, except for pigeon pea with PR (Figure 1).

Maize and pigeon pea in the soil fertilized with PR had biomass accumulation in shoots and roots significantly lower than in their respective treatments with the more soluble $\mathrm{P}$ source McP. Conversely, buckwheat and forage radish showed similar values of biomass production between the two sources of phosphate (PR and $\mathrm{McP}$ ). Evaluated in terms of biomass yield, the AEI of the PR was extremely low with pigeon pea, intermediate with maize, and high with buckwheat and forage radish (Table 1). When evaluated in terms of total $\mathrm{P}$ acquired (i.e. biomass $\mathrm{P}$ content), buckwheat performed even better than forage radish.

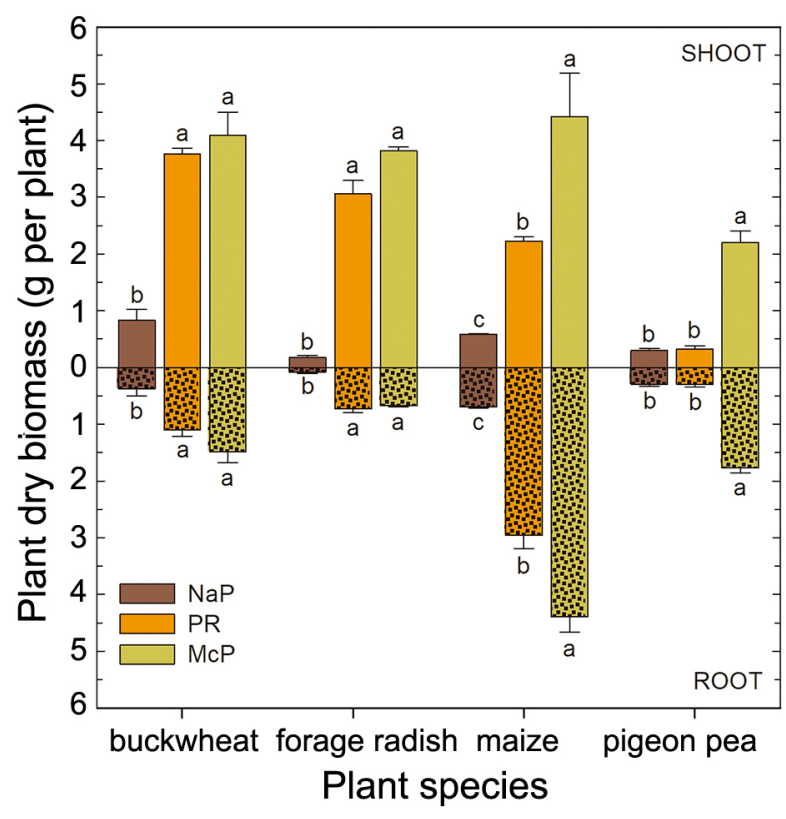

Figure 1 - Dry biomass of shoots and roots of four plant species (buckwheat, forage radish, maize, and pigeon pea) grown with three $P$ sources [No added $P$ (NaP), Phosphate Rock (PR), and Monocalcium Phosphate (McP)] in Experiment 1. Bars show means of three replicates whereas vertical lines show one standard error. Within a plant species and plant part (root or shoot), different letters indicate significant differences among $P$ sources (Tukey test at 0.05 probability degree).

Table 1 - Agronomic Efficiency Index of the Phosphate Rock Itafós considering total biomass (root + shoot) production and total $P$ content (root $\mathrm{P}+$ shoot $\mathrm{P}$ ) of four plant species in two cropping systems and two experiments.

\begin{tabular}{|c|c|c|c|c|}
\hline \multirow[b]{3}{*}{$\begin{array}{l}\text { Cropping system / plant } \\
\text { species }\end{array}$} & \multicolumn{4}{|c|}{ Agronomic Efficiency Index (\%) } \\
\hline & \multicolumn{2}{|c|}{ Experiment 1} & \multicolumn{2}{|c|}{ Experiment 2} \\
\hline & $\begin{array}{c}\text { Total } \\
\text { biomass }\end{array}$ & $\begin{array}{c}\text { Total } \\
\text { P content }\end{array}$ & $\begin{array}{c}\text { Total } \\
\text { biomass }\end{array}$ & $\begin{array}{c}\text { Total } \\
\text { P content }\end{array}$ \\
\hline Buckwheat & 83.7 & 66.4 & 92.2 & 99.8 \\
\hline Forage radish & 83.6 & 53.3 & - & - \\
\hline Maize & 51.8 & 27.6 & 22.0 & 13.3 \\
\hline Pigeon pea & 0.3 & -1.5 & - & - \\
\hline Buckwheat / Maize & - & - & 29.8 & 20.3 \\
\hline
\end{tabular}

Maize and pigeon pea had higher values of root to shoot biomass ratios than buckwheat and forage radish, but these values remained nearly unchanged with $\mathrm{P}$ sources for all four-plant species (average of three $\mathrm{P}$ sources of 1.19 for maize, 0.91 for pigeon pea, 0.37 for buckwheat, and 0.28 for forage radish). Although expected, and sometimes observed in species like wheat and chickpea (Pearse et al., 2006), increases in root to shoot ratios under limited $P$ supply was not observed in our study.

We studied crop species of four different plant families, three dicots and one monocot. The trend usually observed among several plant species is that dicots make a more effective use of rock $\mathrm{P}$ than monocots, explained by the operation of root-induced processes, such as the higher Ca quantities taken up by dicots than monocots, driving a higher dissolution of the Ca phosphate minerals (e.g. apatite) in rocks and by the greater ability of dicots to acidify the rhizosphere and solubilize $\mathrm{P}$ compounds. $\mathrm{P}$ acquisition traits, however, are plant species-specific and access only some forms of P. Pigeon pea, for example, mobilizes $\mathrm{P}$ from Fe phosphates through root exudation of piscidic acid (Ae et al., 1990), which might explain its low capacity to mobilize $\mathrm{P}$ from the dominant Ca phosphates of PR Itafós.

The results of our study confirm the greater ability of buckwheat to take up P of low watersoluble PRs, reported earlier by Raij and Diest (1979). Buckwheat also changed the size of five soil inorganic $\mathrm{P}$ pools, including the less soluble $\mathrm{Ca}-, \mathrm{Fe}-$, and $\mathrm{Al}-$ bound $\mathrm{P}$ ones (Teboh and Franzen, 2011). Root-induced processes like release of carboxylates, such as tartrate ${ }^{2-}$ and citrate $^{3-}$, when plant is grown under low soil $\mathrm{P}$ availability, and root net proton extrusion, resulting from the plant alkaline uptake pattern and promoting rhizosphere acidification, are two main mechanisms underlying the $\mathrm{P}$ acquisition trait in this species (Gerke, 2015; Hallama et al., 2019; Raij and Diest, 1979). Cultivation as single crop might be a management tool to increase soil $\mathrm{P}$ availability to subsequent crops. Based on its distinguished performance in the current study, buckwheat was chosen to be tested in the second experiment for its potential to facilitate the access of maize to $\mathrm{P}$ from PR.

Experiment 2 - In this experiment, we questioned if maize plants could benefit from the $\mathrm{P}$ mobilization strength of buckwheat, taking up more P from PR when grown interplanted with buckwheat plants. The effects of cropping system, plant species, and P source on shoot biomass, shoot $\mathrm{P}$ concentration, and plant $\mathrm{P}$ content were ascertained with the two- and three-ways ANOVA and highly significant interaction effects were detected. Maize and buckwheat showed small shoot biomass yields with no application of $\mathrm{P}(\mathrm{NaP})$ and reacted distinctly to $\mathrm{P}$ application depending on the form the nutrient was applied and the cropping system adopted (Figures 2A and 2B). 

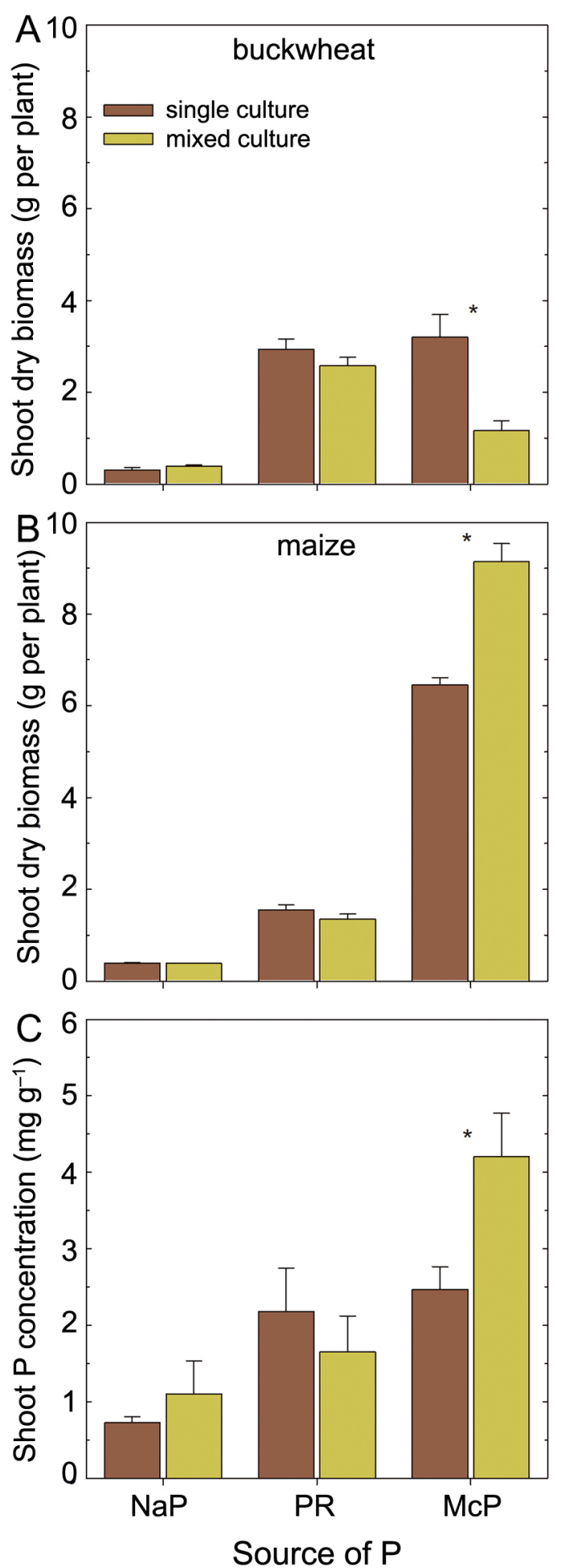

Figure 2 - Shoot biomass and shoot $P$ concentration of buckwheat and maize plants grown with three $P$ sources [No added $P(\mathrm{NaP})$, Phosphate Rock (PR), and Monocalcium Phosphate (McP)] and two cropping systems (single and mixed cropping) in Experiment 2. Bars show the means of three replicates whereas vertical lines show one standard error. Asterisks indicate significant differences between cropping systems (Tukey test at 0.05 probability degree).
Mixing plants of maize and buckwheat in the soil amended with PR, however, did not increase growth or $\mathrm{P}$ nutrition of the maize plants, where neither the shoot biomass nor the shoot $\mathrm{P}$ concentration of maize was altered by the presence of buckwheat plants (Figures 2B and $2 \mathrm{C}$ ). Values of shoot $\mathrm{P}$ concentration for buckwheat and maize are presented together in Figure 2C because the ANOVA indicated no difference between the two plant species. These results suggest that $\mathrm{P}$ of PR mobilized by buckwheat roots did not reach those of maize in significant amounts. Although roots of both plant species were strongly intermingled in the entire soil volume, maize plants could not benefit from the $\mathrm{P}$ mobilizing capacity of buckwheat. The reasons for this lack of benefit are unknown, but it is possibly due to the (small) amounts of P mobilized by buckwheat. Although we used a sandy soil with low $\mathrm{P}$ adsorption capacity, the amounts of $\mathrm{P}$ solubilized by buckwheat roots that entered the soil solution might have been small and hence insufficient to diffuse away from the rhizosphere of buckwheat and reach that of maize.

Insignificant changes were also seen on biomass production and shoot $\mathrm{P}$ concentration of buckwheat. Cultivated with maize plants, buckwheat plants reached $88 \%$ of shoot biomass and $79 \%$ of shoot $\mathrm{P}$ concentration of plants cultivated in single cropping system. The results indicate, therefore, that neither facilitation nor competition significantly affected plants of both species in the mixed cropping treatments that had PR as P source compared to their respective single cropping treatments. In the literature, studies have reported conflicting results on these interspecific root interactions. While some studies registered cases of enhanced nutrient acquisition and growth by the non-P mobilizer plant species (Duchene et al., 2017; Dissanayaka et al., 2015), no beneficial effects of one species on the other were observed in others (Li et al., 2010; Li et al., 2018), even when increase of P availability in the rhizosphere of the $\mathrm{P}$ mobilizer species occurred (Betencourt et al., 2012). The relatively short period and growth stage of plants in many assays and the differential growth and nutrient demand rate of the species, with eventual dominance of one of them, have been proposed to explain the inconsistencies observed.

Modeling and numerical simulation studies done recently revealed that facilitation and competition occur when the rhizosphere of neighbor roots overlap (Parseval et al., 2017). Absorption of nutrients as well as release of compounds by roots create diffusion gradients and, respectively, depletion and accumulation zones around them. Roots, therefore, interact with each other through facilitation or competition when their depletion and/or accumulation zones overlap. The size of these root zones of influence and their degree of overlapping are thus crucial in determining the type and magnitude of root interaction. The size of these root zones of influence varies depending on the absorption and release rates of roots and on the diffusive properties of soils (e.g. water content, binding capacity) and molecules (e.g. nutrients, ligands) 
(Parseval et al., 2017; Raynaud et al., 2008); therefore, cases of inter-root competition, inter-root facilitation, and no interaction might be expected to alternate in space and time in mixed cropping systems.

The water-soluble $\mathrm{P}$ source $\mathrm{McP}$ showed significant differences in shoot biomass and $\mathrm{P}$ concentration of both maize and buckwheat between the two cropping systems (single and mixed) (Figure 2). Maize plants grown with buckwheat had a statistically significant $30 \%$ higher shoot biomass yield than those grown with other maize plants. On the other hand, buckwheat plants in mixed cropping had only $36 \%$ of the shoot biomass yield of their respective ones in single cropping. Plants of both species showed higher shoot $\mathrm{P}$ concentration in the mixed than in the single crop (Figure $2 \mathrm{C}$ ). The higher supply of readily available $\mathrm{P}$ conferred by $\mathrm{McP}$ sustained a higher maize growth, which enabled plants to take up more $\mathrm{P}$, and likely other nutrients and water, than in the PR treatment (Figure 3). Differences were also observed between the cropping systems, where maize produced more biomass in the mixed cropping than in the single crop and this occurred at the expenses of the neighbor buckwheat plants. Besides the differences in plant biomass, the interplant and interspecific competition (buckwheatmaize) resulted in higher amounts of $\mathrm{P}$ uptake than the interplant and intraspecific competition (maize-maize) (Figure 3). This overyielding of one plant to the detriment

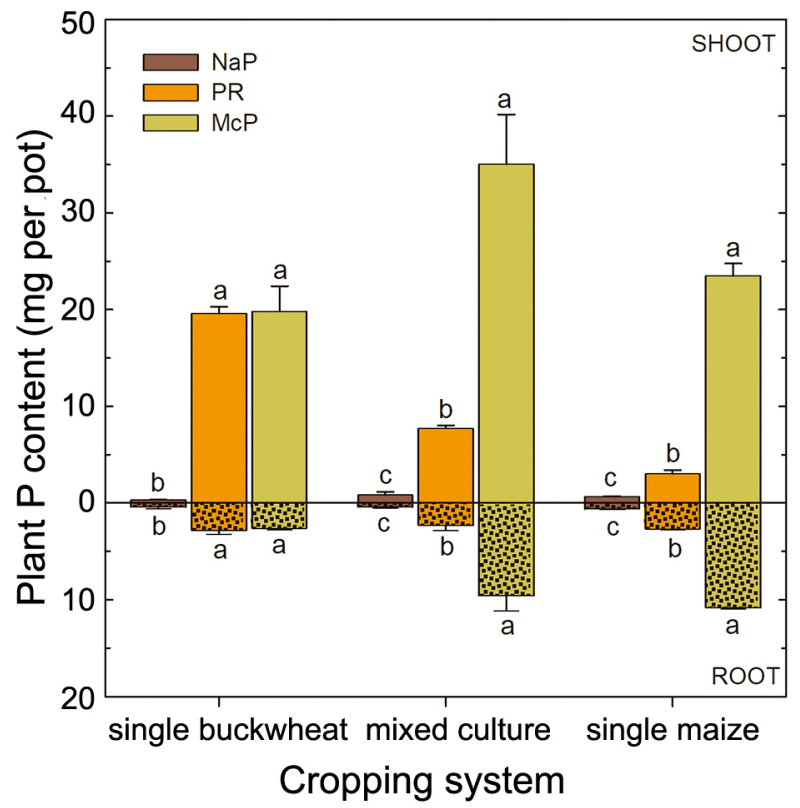

Figure 3 - The $P$ content of shoots and roots of buckwheat and maize plants grown with three $P$ sources [No added $P(\mathrm{NaP})$, Phosphate Rock (PR), and Monocalcium Phosphate (McP)] and two cropping systems (single and mixed cropping) in Experiment 2. Bars show the means of three replicates whereas vertical lines show one standard error. Within a cropping system and plant part (shoot or root), different letters indicate significant differences among $\mathrm{P}$ sources (Tukey test at 0.05 probability degree). of others is known as selection effect and it occurs when the species that takes up most $\mathrm{P}$ (or other nutrients, water) in a single crop (monoculture) increases in abundance in mixture at the expense of the other species (Brooker et al., 2015). The high growth and $P$ acquisition of maize also contributed to lower the AEI values of PR in the mixed species system - values about $30 \%$ for total plant biomass and $20 \%$ for total plant $\mathrm{P}$ content (Table 1).

The contributions of facilitation and competition vary depending on time, neighbors, and environmental conditions (e.g. resource availability) that regulate interactions between plants and the soil. According to the stress-gradient hypothesis, facilitative (positive) interactions are more often seen under higher environmental stress (e.g. low nutrient availability), whereas competitive (negative) interactions are more common under less stressful conditions (e.g. high nutrient availability) (Brooker et al., 2015). Our results, however, could support only in part the stress-gradient hypothesis since we did not observe significant positive interactions between maize and buckwheat plants under conditions of low soil $\mathrm{P}$ availability (i.e. higher environmental stress).

In conclusion, we tested four plant species and a combination of two of them to complement each other under an environmental context of a sandy, low-P soil amended with a non-conventional $\mathrm{P}$ fertilizer, and obtained an unsatisfactory outcome for the mixed cropping system. Although the potential of buckwheat to mobilize P from a sparingly soluble material was confirmed here, simply interplanting it did not improve growth or $\mathrm{P}$ nutrition of maize. Testing plant species in single and mixed cropping systems allows assessing the potential of their functional traits and their interactions. This information could be used to improve cropping system designs and promote a better use of environmental resources.

Buckwheat may be grown in soils receiving slow dissolution $\mathrm{P}$ fertilizers to mobilize rock $\mathrm{P}$ and make it available to subsequent crops in intercropping systems. The increase in soil $\mathrm{P}$ availability could be accomplished with mineralization of organic $\mathrm{P}$ and release of free inorganic cell $\mathrm{P}$ during microbial decomposition of buckwheat biomass in the soil. This potential of buckwheat is under investigation in our ongoing research.

\section{Acknowledgments}

We thank the São Paulo Research Foundation (FAPESP) for funding the study, grants \#2016/20186-0 and \#2018/15754-4.

\section{Authors' Contributions}

Conceptualization: Lopes, V.A.; Mariano, E.D. Data acquisition: Lopes, V.A.; Wei, M.C.F.; Cardoso, T.M.; Casagrande, J.C. Data analysis: Lopes, V.A.; Mariano, E.D. Design of methodology: Lopes, V.A.; Mariano, E.D. Writing and editing: Lopes, V.A.; Wei, M.C.F.; Martins, E.S.; Casagrande, J.C.; Mariano, E.D. 


\section{References}

Ae, N.; Arihara, J.; Okada, K.; Yoshihara, T.; Johansen, C. 1990. Phosphorus uptake by pigeon pea and its role in cropping systems of the Indian Subcontinent. Science 248: 477-480.

Betencourt, E.; Duputel, M.; Colomb, B.; Desclaux, D.; Hinsinger, P. 2012. Intercropping promotes the ability of durum wheat and chickpea to increase rhizosphere phosphorus availability in a low P soil. Soil Biology \& Biochemistry 46: 181-190.

Brooker, R.W.; Bennett, A.E.; Cong, W.; Daniell, T.J.; George, T.S.; Hallett, P.D.; Hawes, C.; Iannetta, P.P.M.; Jones, H.G.; Karley, A.J.; Li, L.; McKenzie, B.M.; Pakeman, R.J.; Paterson, E.; Schöb, C.; Shen, J., Squire, G.; Watson, C.A.; Zhang, C.; Zhang, F.; Zhang, J.; White, P.J. 2015. Improving intercropping: a synthesis of research in agronomy, plant physiology and ecology. New Phytologist 206: 107-117.

Chien, S.H.; Prochnow, L.I.; Tu, S.; Snyder, C.S. 2011. Agronomic and environmental aspects of phosphate fertilizers varying in source and solubility: an updated review. Nutrient Cycling in Agroecosystems 89: 229-255.

Dissanayaka, D.M.S.B.; Maruyama, H.; Masuda, G.; Wasaki, J. 2015. Interspecific facilitation of $P$ acquisition in intercropping of maize with white lupin in two contrasting soils as influenced by different rates and forms of P supply. Plant and Soil 390: 223-236.

Duchene, O.; Vian, J.; Celette, F. 2017. Intercropping with legume for agroecological cropping systems: complementarity and facilitation processes and the importance of soil microorganisms. A review. Agriculture, Ecosystems and Environment 240: 148-161.

Gerke, J. 2015. The acquisition of phosphate by higher plants: effect of carboxylate release by the roots: a critical review. Journal of Plant Nutrition and Soil Science 178: 351-364.

Hallama, M.; Pekrun, C.; Lambers, H.; Kandeler, E. 2019. Hidden miners: the roles of cover crops and soil microorganisms in phosphorus cycling through agroecosystems. Plant and Soil 434: 7-45.

Hauggaard-Nielsen, H.; Jensen, E.S. 2005. Facilitative root interactions in intercrops. Plant and Soil 274: 237-250.

Li, H.; Shen, J.; Zhang, F.; Marschner, P.; Cawthray, G.; Rengel, Z. 2010. Phosphorus uptake and rhizosphere properties of intercropped and monocropped maize, faba bean, and white lupin in acidic soil. Biology and Fertility of Soils 46: 79-91.

Li, X.; Wang, C.; Zhang, W. 2018. The role of complementarity and selection effects in $\mathrm{P}$ acquisition of intercropping systems. Plant and Soil 422: 479-493.

Manschadi, A.M.; Kaul, H.; Vollmann, J.; Eitzinger, J.; Wenzel, W. 2014. Developing phosphorus-efficient crop varieties: an interdisciplinary research framework. Field Crops Research 162: 87-98.
Parseval, H.; Barot, S.; Gignoux, J.; Lata, J-C.; Raynaud, X. 2017. Modelling facilitation or competition within a root system: importance of the overlap of root depletion and accumulation zones. Plant and Soil 419: 97-111.

Pavinato, P.S.; Rodrigues, M.; Solthangheisi, A.; Sartor, L.R.; Withers, P.J.A. 2017. Effects of cover crops and phosphorus sources on maize yield, phosphorus uptake, and phosphorus use efficiency. Agronomy Journal 109: 1-9.

Pearse, S.J.; Veneklaas, E.J.; Cawthray, G.R.; Bolland, M.D.A.; Lambers, H. 2006. Carboxylate release of wheat, canola and 11 grain legume species as affected by phosphorus status. Plant and Soil 288: 127-139.

Prochnow, L.I.; Quispe, J.F.S.; Francisco, E.A.B.; Braga, G. 2006. Effectiveness of phosphate fertilizers of different water solubilities in relation to soil phosphorus adsorption. Scientia Agricola 63: 333-340.

Raij, B.; Diest, A. 1979. Utilization of phosphate from different sources by six plant species. Plant and Soil 51: 577-589.

Raynaud, X.; Jaillard, B.; Leadley, P.W. 2008. Plants may alter competition by modifying nutrient bioavailability in rhizosphere: a modeling approach. The American Naturalist 171: 44-58.

Stamford N.P.; Santos, P.R.; Santos, C.E.S.; Freitas, A.D.S.; Dias, S.H.L.; Lira Junior, M.A. 2007. Agronomic effectiveness of biofertilizers with phosphate rock, Sulphur and Acidithiobacillus for yam bean grown on a Brazilian tableland acidic soil. Bioresource Technology 98: 1311-1318.

Stamford, N.P.; Simões Neto, D.E.; Freitas, A.D.S.; Oliveira, E.C.A.; Oliveira, W.S.; Cruz, L. 2016. Rock biofertilizer and earthworm compost on sugarcane performance and soil attributes in two consecutive years. Scientia Agricola 73: 29-33.

Teboh, J.M.; Franzen, D.W. 2011. Buckwheat (Fagopyrum esculentum Moench) potential to contribute solubilized soil phosphorus to subsequent crops. Communications in Soil Science and Plant Analysis 42: 1544-1550.

Withers, P.J.A.; Rodrigues, M.; Soltangheisi, A.; Carvalho, T.S.; Guilherme, L.R.G.; Benites, V.M.; Gatiboni, L.C.; Sousa, D.M.G.; Nunes, R.S.; Rosolem, C.A.; Andreote, F.D.; Oliveira Jr, A.; Coutinho, E.L.M.; Pavinato, P.S. 2018. Transitions to sustainable management of phosphorus in Brazilian agriculture. Scientific Reports 8: 2537.

Yagi, R.; Quadros, T.C.F.; Martins, B.H.; Andrade, D.S. 2020. Maize yields and carbon pools in response to poultry litter, rock phosphate and P-solubilizing microorganisms. Scientia Agricola 77: e20180141. 